\title{
Development and genesis of organic matter pore for Jurassic shale in the middle part of Northern Qaidam \\ Basin
}

\author{
YUNPENG ZHANG ${ }^{1 *}$, YUHONG LI ${ }^{2}$, YONGHONG $\mathrm{LI}^{3}$
}

Xi'an Center of China Geological Survey/ Northest China Center for Geoscience Innovation, Xi'an 710054, Shaanxi, China ("correspondence: zypcgs@163.com)

${ }^{2}$ Xi'an Center of China Geological Survey/ Northest China Center for Geoscience Innovation, Xi'an 710054, Shaanxi, China (lyuhong@mail.cgs.gov.cn)

${ }^{3}$ Qinghai Bureau of Coal Geology, Xining 810001, Qinghai, China (lyh6807@163.com)

The Jurassic shale in Northern Qaidam Basin is characterized by high organic carbon content, large thickness and wide distribution. However, due to immaturity-low maturity of organic matter, the formation and characterization of shale gas in this area are restricted. Through the heating experiment in the open system, the development characteristics of organic matter pore in shale under different temperatures can be systematically described. It is analyzed that organic matter pore favor to develop during the range of $200^{\circ} \mathrm{C}-400^{\circ} \mathrm{C}$, with a large number of pore and extremely developed nano pore, network connection can finally form. After that, with the further increasing of temperature, the pore will appear "collapse" phenomenon, which will inhibit the occurrence of shale gas. Besides, the pore development of organic matter is also heterogeneous, and the pore development of different organic matter macerals is different. The pore development in vitrinite and exinite is relatively slow, and the transformation of organic matter is not complete. However, the pore development of organic matter macerals, mainly composed of bituminite, alginite and amorphous body, are early and strong, and connectivity between pore is good, which are the major contributors to shale gas reservoir space. In addition, combined with EDS analysis, it is considered that the development of organic matter pore is mainly controlled by the weight percentage of elements and the content of alkaline earth elements such as $\mathrm{Ca}, \mathrm{Mg}$. 